\title{
Mid Term Results of Distal Femoral Fractures Treated with a Polyaxial Locking Plate: A Multi-Center Study
}

\author{
J.B. Erhardt ${ }^{*}, 1$, M. Vincenti ${ }^{1}$, J. Pressmar ${ }^{2}$, F.A. Kuelling ${ }^{1}$, C. Spross ${ }^{1}$, F. Gebhard ${ }^{2}$ and G. Roederer ${ }^{2}$ \\ ${ }^{1}$ Klinik für Orthopädie und Traumatologie, Kantonsspital St. Gallen, Switzerland \\ ${ }^{2}$ Klinik für Unfall-, Hand-, Plastische-, Wiederherstellungschirurgie, Universitätsklinik Ulm, Germany
}

\begin{abstract}
Objective: Locking plates have become a standard implant in the treatment of distal femoral fractures. Newer designs allow polyaxial screw placement as well as the ability to lock the lag screws.

Methods: The consecutive multi-centre study cohort consists of all distal femoral fractures treated with the NCB ${ }^{\circledR}$ Distal Femur plate (Zimmer, Warsaw, USA) and a minimum follow-up of twelve months. Fracture classification according the $\mathrm{AO} / \mathrm{OTA}$ system and the trauma mechanism radiological evaluation and complications were documented. Clinical evaluation consisted of the Short Form SF12 questionnaire (SF12), the Hospital for Special Surgery Score (HSS) and clinical assessment of range of motion.

Results: Twenty-five patients with twenty-six fractures were available for follow-up with a minimum required follow-up of twelve months. $81 \%$ of the fractures were intra-articular. $48 \%$ of the patients were multi-traumatised, $38 \%$ having open fractures. All except two went to union (92\%) with the primary procedure. The HSS Score was 79 (32-99) and the SF 12 (physical and mental) 40 (19-57) and 54 (21-66) at follow-up. There were five patients requiring surgical revision (19\%).

Conclusion: These fractures are often combined with concomitant injuries. Using modern locked implants high union rates can be achieved with a good function and patient satisfaction when respecting biologic and biomechanical principles.
\end{abstract}

Keywords: Locking plates, polyaxial, distal femur fracture, osteosynthesis, NCB.

\section{INTRODUCTION}

Since the introduction of locking plates a decade ago [1] they have widely replaced conventional non locking implants in the treatment of distal femoral fractures. In the distal femur, the locking mechanism provided improved resistance against the adduction moments compared to conventional implants like the condylar buttress plate and therefore loss of reduction and varus malalignment could be reduced [2]. Also the simple mode of applying these systems and the possibility of using minimally invasive techniques facilitated the fast and wide spread application of these plating systems within a short time, even though conventional angular stable implants like the blade plate were available and showed good results [3]. But despite the early success of locking plates the new mechanical properties also resulted in new problems. The mode of healing seems to be different compared to conventional systems regarding callus formation. In addition, there is a risk of producing too much rigidity leading to diminished stimulation of healing resulting in non union and implant failure [4]. It turned out that the principles of dynamic osteosynthesis seem to be paramount to clinical success of these implants [5]. Additionally, locked implants gained further properties combining the advantages of conventional

*Address correspondence to this author at the Klinik für Orthopädie und Traumatologie, Kantonsspital St. Gallen, CH-9007 St. Gallen, Switzerland; Tel: +41 71494 3483; E-mail: Johannes.Erhardt@kssg.ch plates, e.g. polyaxiality and the application of lag screws. In our retrospective case series we present all distal femoral fractures, with $81 \%$ intraarticular fractures, treated in two major Trauma Centres in Switzerland and Germany with a complete one year clinical and radiological follow up after the introduction of the NCB polyaxial locking system applied with standardized criteria of modern dynamic osteosynthesis.

\section{MATERIALS AND METHODS}

The consecutive study cohort consists of all distal femoral fractures treated in both institutions with the $\mathrm{NCB}^{\circledR}$ Distal Femur plate (Zimmer, Warsaw, USA) and a minimum of twelve months since surgery. Pathological fractures and periprosthetic fractures were excluded. Patients were enrolled retrospectively and a final follow-up was performed. The main investigators at each hospital examined all patients personally.

\section{Implant and Locking Mechanism}

The $\mathrm{NCB}^{\circledR}$ DF plate is an implant that combines the properties of a conventional plate with the benefits of a locking plate (Fig. 1). The plate is available in left and right versions, each in 5-hole $(167 \mathrm{~mm})$, 9-hole $(246 \mathrm{~mm})$, and 13 hole $(324 \mathrm{~mm})$ lengths. Self-taping cortical or cancellous screws can be used to reduce or lag the fracture while providing tactile feedback to the surgeon about the quality of 
the bone. In addition, the screws can be locked with the NCB locking caps with a torque of $6 \mathrm{Nm}$, up to an angle of total of $30^{\circ}$. In contrast to other locking mechanisms, the $\mathrm{NCB}$ provides no absolute angular stability, but one NCB screw will resist a load of $225 \mathrm{~N}$ in a distance of $25 \mathrm{~mm}$ from the plate. A radiolucent device allows the minimal invasive application of the plate. In the presented study, no failures of the locking mechanism were reported.

\section{Surgical Technique}

For intra-articular fractures $(\mathrm{n}=21)$, visualisation of the joint through a lateral approach and anatomic reduction was performed combined with minimally invasive plate application (MIPO) to the proximal fragment. The anatomic reduction and absolute stability was either achieved with a separate lag screw or lagging through the plate with an NCB screw. In eleven cases an external fixator was applied as the primary treatment and also used as an indirect reduction tool during definitive treatment. If an open reduction was necessary, a biological surgical technique was employed. This means that the approach to the fracture is only very sparingly dissected, the muscle coverage of the bone fragments is preserved, and the periosteum is not removed [6]. Additionally, interfragmentary compression is avoided in order to achieve a dynamic osteosynthesis with consequent callus formation. Reduction of the fragments occurred in a combined direct/ indirect manner, achieved with the aid of the anatomically pre-formed plate. Locking plate osteosynthesis was done using a dynamic or bridging technique, e.g. using long plates to reduce rigidity [5]. For simple transverse fracture patterns, three holes around the fracture gap were left empty, in a comminuted situation the holes in the plate adjacent to the comminuted zone were used. This allows an optimized stress distribution on the plate and reduces the risk of plate breakage [7]. Angular stabilization by adding NCB locking caps was generally done at the end of the procedure. The shape of the screws causes the plate to lift away slightly from the bone so that it can act as an internal fixator. The periosteal blood flow of the bone is therefore retained.

Patients underwent early mobilization and continuous passive motion. Weight bearing ranged from no weight bearing to partial weight bearing, depending on fracture stability and the ability of the patient.
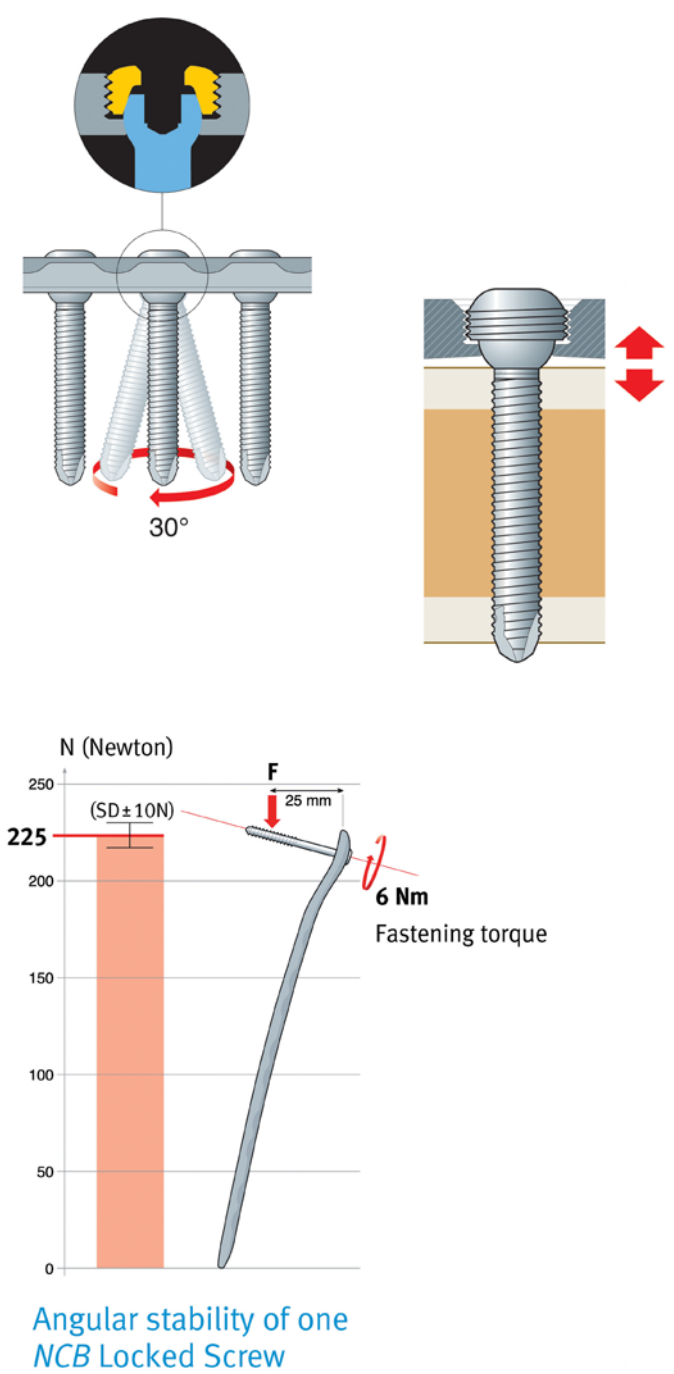

Fig. (1). Implant locking mechanism and MIPO Jig.

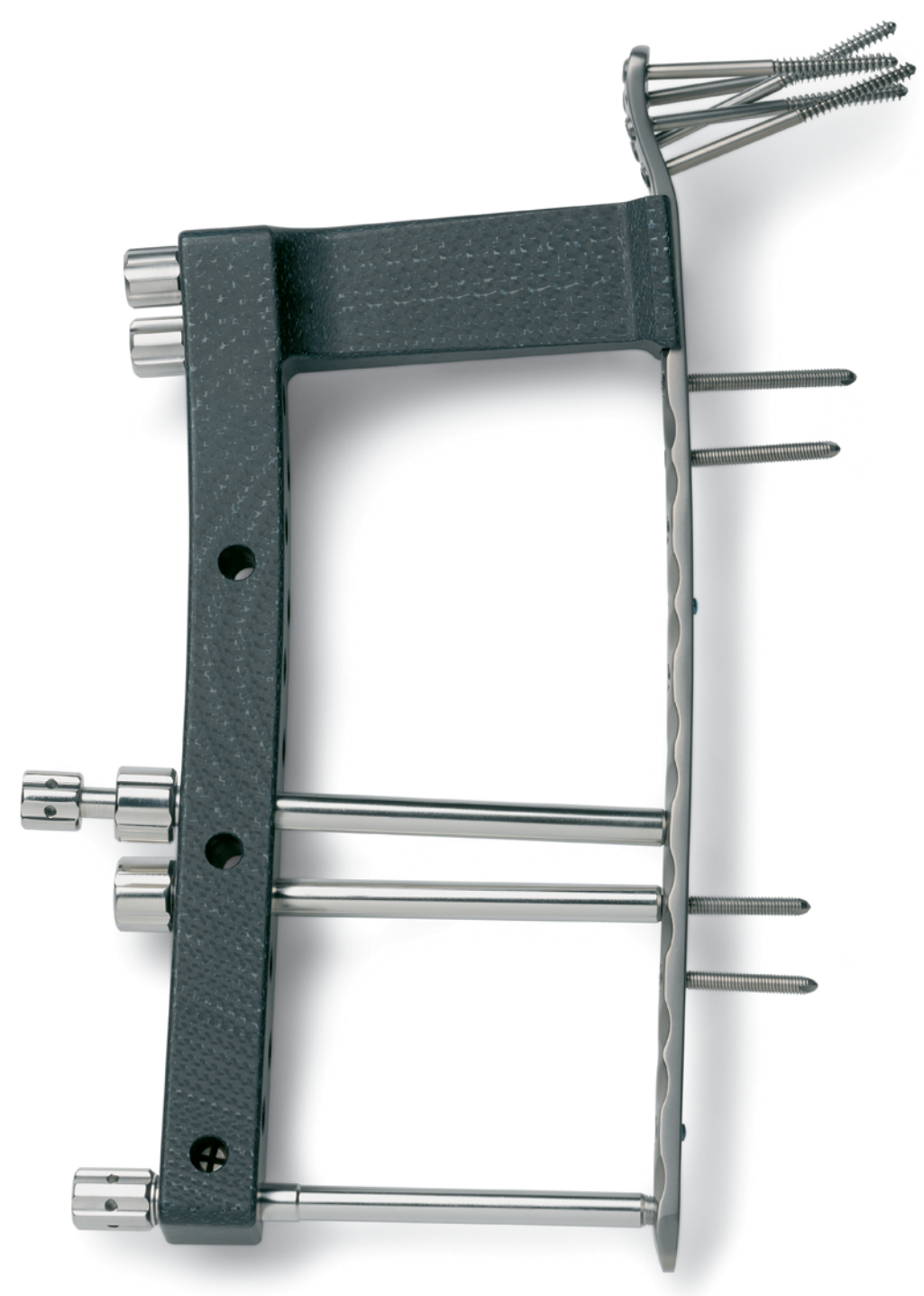




\section{Outcome Parameters}

The following parameters were evaluated at follow-up after a minimum of one year: HSS Score (0-100), SF 12 Score, range of motion, complications, surgical revisions, radiological union and mal-union, or non-union. Union was defined as visible callus in two planes and full weight bearing without pain, non-union as no callus formation or fracture of the plate after six months and mal-union as a shortening of $>2 \mathrm{~cm}$ or valgus/varus $>5^{\circ}$. Also return to work was evaluated.

Results are presented descriptively using mean and range for continuous variables and percentages for categorical variables. Statistics were performed with SPSS Software 19.0 (SPSS Inc., Chicago IL, USA).

\section{RESULTS}

Twenty-five patients with twenty-six fractures were available for follow-up. Nineteen fractures were treated at a
Cantonal Hospital in Switzerland and seven at a University Hospital in Germany. Eleven patients were female and fourteen male with an average age of 53 years (19-86). The average body mass index was 26 (18-40). According to the $\mathrm{AO} / \mathrm{OTA}$ classification, five fractures $(19 \%)$ were classified as type $\mathrm{A}$, two (8\%) as type $\mathrm{B}$ and nineteen (73\%) as type $\mathrm{C}$ fractures. Hence, the majority of the fractures $(81 \%)$ were intra-articular (Fig. 2). Forty-eight per cent of the patients were multi-traumatized. Ten (38\%) were open, and sixteen $(62 \%)$ were closed fractures. Eleven patients $(42 \%)$ had a traffic accident, nine $(35 \%)$ a simple fall, two $(8 \%)$ an occupational accident, one (4\%) a sports accident, and three $(12 \%)$ a fall from height. The 13-hole plate was used eleven times, the 9-hole plate nine times, and the 5-hole plate six times. Details about patient demographics and fractures are presented in Table 1.

The average follow-up was 36.5 months (13.0-76.4). All except two fractures healed $(92 \%)$ with the primary procedure. However, according to the criteria "visible callus in two planes and full weight bearing without pain" all

Table 1. Patient Demographics and Fracture Details

\begin{tabular}{|c|c|c|c|c|c|c|c|}
\hline 1 & 19 & M & 26 & $\mathrm{~A} 2$ & Yes & open & MVA \\
\hline 3 & 50 & M & 26 & A2 & Yes & closed & MVA \\
\hline 4 & 66 & $\mathrm{~F}$ & 28 & $\mathrm{C} 1$ & No & closed & MVA \\
\hline 6 & 41 & M & 36 & $\mathrm{~A} 3$ & Yes & open & Occupational \\
\hline 7 & 48 & M & 24 & $\mathrm{C} 3$ & Yes & closed & Sports accident \\
\hline 8 & 42 & M & 27 & $\mathrm{C} 3$ & Yes & closed & Fall from height \\
\hline 9 & 44 & $\mathrm{~F}$ & 23 & $\mathrm{~B} 2$ & Yes & closed & Fall from height \\
\hline 13 & 22 & $\mathrm{~F}$ & 25 & $\mathrm{C} 3$ & No & open & MVA \\
\hline 14 & 72 & $\mathrm{~F}$ & 40 & $\mathrm{C} 1$ & No & closed & Simple fall \\
\hline 15 & 62 & M & 19 & $\mathrm{C} 1$ & No & open & Occupational \\
\hline 16 & 48 & $\mathrm{~F}$ & 20 & $\mathrm{C} 2$ & Yes & open & MVA \\
\hline 17 & 52 & M & 25 & $\mathrm{C} 1$ & No & closed & Simple fall \\
\hline 18 & 71 & $\mathrm{~F}$ & 21 & B2 & No & closed & Simple fall \\
\hline 19 & 50 & M & 28 & $\mathrm{C} 3$ & Yes & closed & MVA \\
\hline 20 & 27 & M & 29 & $\mathrm{C} 3$ & No & closed & Fall from height \\
\hline 25 & 82 & F & 31 & $\mathrm{~A} 1$ & No & closed & Simple fall \\
\hline
\end{tabular}




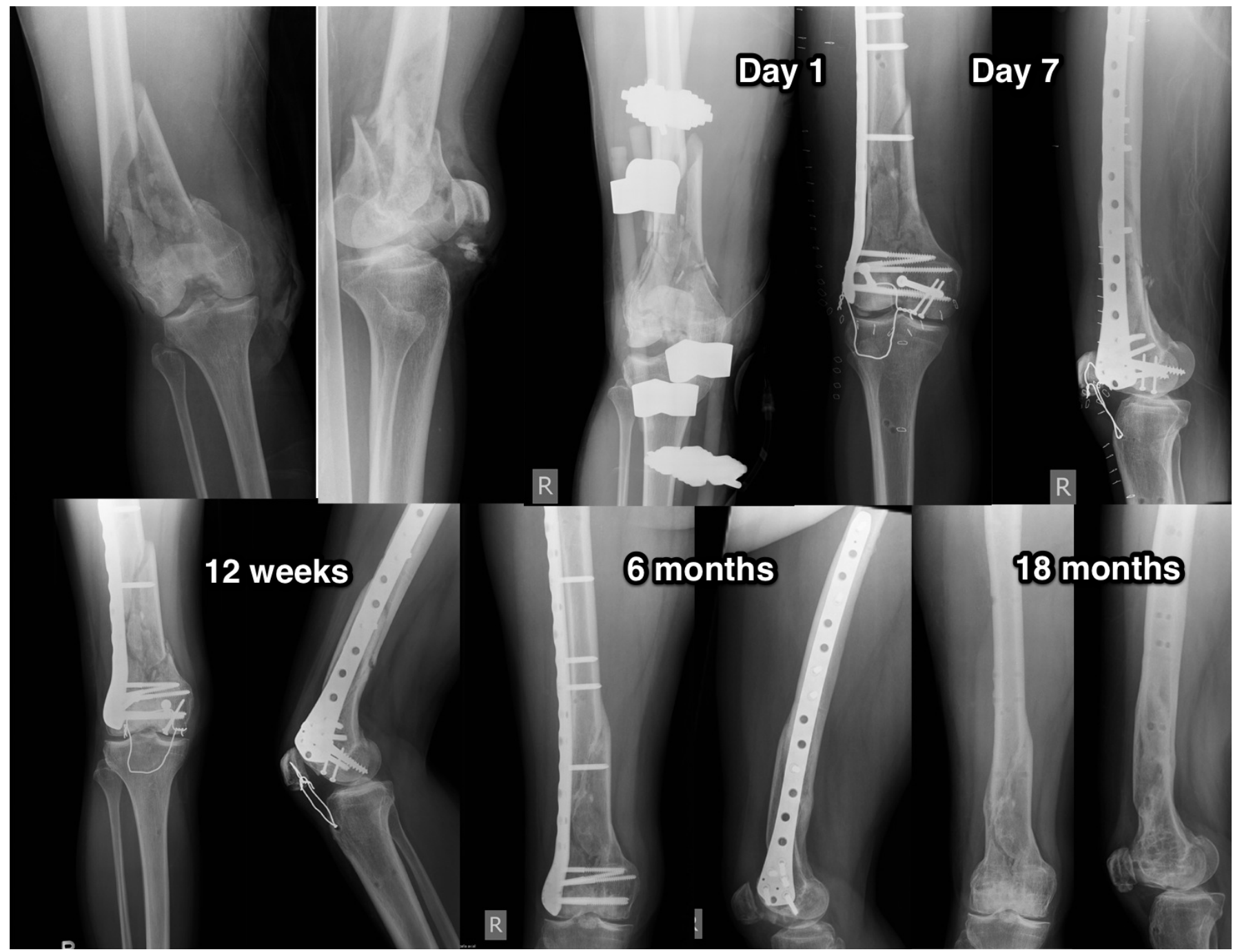

Fig. (2). The radiological course of a complex distal intraarticular femur fracture of a 50-year-old woman after a high-energy trauma.

fractures were healed at the final follow-up. Range of motion at the knee joint of the operated side reached $117^{\circ}$ on average (range 70-140) which corresponds to $90 \%$ versus the non-operated side. The mean HSS Score was 79 (32-99, SD18) with 12 excellent, 7 good, two poor and 5 fair results. At follow-up the mean SF 12 reached 40 (19-57, SD11.8) for the physical and 54 (21-66, SD10.6) for the mental component. Six of the 23 patients $(26 \%)$ had to use a walking aid at the final follow-up. The average age of these six patients was 66 (48-86). Of fourteen patients working before the accident, five did not return to work. Outcome parameters are presented in Table 2.

Overall, five fractures had to be revised (19\%): two nonunions, one compartment syndrome including a deep infection, one irritating screw tip and one screw penetration into the joint. The two non-unions received bone grafting and went on to union at final follow-up. One of them had two additional revisions due to a deep infection before final follow up. The compartment syndrome was treated with debridement and irrigation. The irritating screw tip and the screw penetrating into the joint were resolved by screw removal. Overall, neither implant breakage nor locking mechanism failure occurred. Additionally, the implant was removed in eight patients (31\%): In five due to Iliotibial tract irritation, in two upon patient request and in one because of patient age (19 years). Details about complications are presented in Table 3 .

\section{DISCUSSION}

Management of distal femoral fractures is challenging and often complicated by concomitant injuries and open fractures. The primary goal is to restore the axis and rotation of the injured femur and to restore the articular surface if necessary. In high-energy injuries to the lower $\operatorname{limb}$ a combination of metaphyseal and intra-articular injuries is found frequently. In order to treat these complex injuries, the specific characteristics of the device used are important. Mechanically, it should provide high primary stability and yet enough flexibility to allow dynamic osteosynthesis, it should be applicable in an angular stable mode, and maintain the reduction until union. In these complex injuries, the time to complete bony union often exceeds six months. These mechanical properties should go along with an easy and flexible way of application and the possibility to use minimally invasive techniques. 
Table 2. Functional and Radiological Outcome

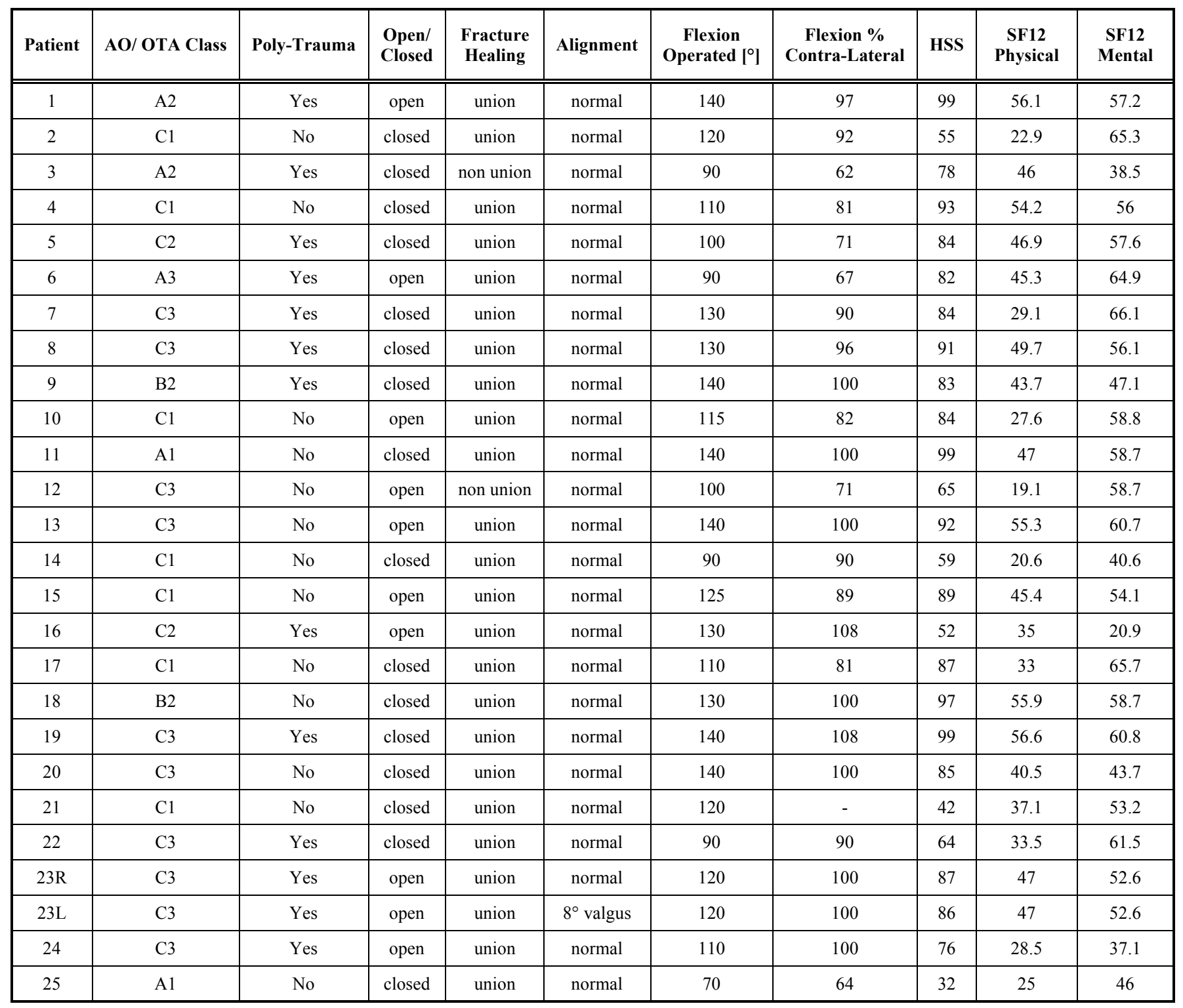

One such implant is the LISS plate (Synthes, Bettlach, Switzerland), which has been in use for a decade now. Recently the largest meta analysis regarding distal femoral fractures using a locked implant has been published [8]. Smith et al. reviewed 694 fractures including 66 periprosthetic fractures, 305 fractures being intraarticular $(\mathrm{AO} 33 \mathrm{C}+33 \mathrm{~B})$ and 130 open fractures. The largest single series included in the study is the case series of Kregor et al. including 99 distal femoral fractures treated with the LISS plate [9]. Smith et al. reports in his heterogenic group an incidence of loss of reduction of nineteen per cent, delayed or non-union of six per cent and implant failure of five per cent. In the case series of Kregor et al., which consists of intraarticular fractures in 57\%; they report primary healing in $93 \%$ of the cases, two non-unions, three infections and five implant failure. The overall reoperation rate in his patient group was eighteen per cent at a mean follow-up period of fourteen months. This is comparable to our results representing the largest case series up to date reviewing distal femoral fractures treated with the polyaxial $\mathrm{NCB}^{\circledR} \mathrm{DF}$ plate.

In our series we report two non-unions. One occurred in a multi-traumatized patient who had received an external fixator before treatment with the $\mathrm{NCB}^{\circledR} \mathrm{DF}$ plate. Three weeks after treatment with the plate he developed a deep wound infection requiring irrigation and debridement twice. In the further course the infection successfully healed. One and a half years later he developed progressive varus deformity of his right lower extremity due to a non-union and concomitant pullout of the plate proximally. The patient received autologous cancellous bone grafting and reosteosynthesis and went to union. The second non-union was after an $\mathrm{II}^{\circ}$ open $\mathrm{AO} / \mathrm{OTA} \mathrm{C} 3$ fracture of the distal femur of a 68 year old smoker which went to union after an autologous bone grafting. Given the high number of multitraumatized patients as well as open fractures in the presented case series, we believe eight per cent non-union is an acceptable number. For instance El-Zayat et al. reported 
Table 3. Complications

\begin{tabular}{|c|c|c|c|c|c|c|c|c|}
\hline Patient & $\begin{array}{c}\text { AO/OTA } \\
\text { Class }\end{array}$ & $\begin{array}{c}\text { Poly- } \\
\text { Trauma }\end{array}$ & $\begin{array}{l}\text { Open/ } \\
\text { Closed }\end{array}$ & $\begin{array}{c}\text { General } \\
\text { Complication }\end{array}$ & $\begin{array}{c}\text { Local } \\
\text { Complication }\end{array}$ & $\begin{array}{c}\text { Technical } \\
\text { Complication }\end{array}$ & Revision & Description \\
\hline 3 & A2 & Yes & closed & & $\begin{array}{l}\text { Hematoma } \\
\text { Wound healing } \\
\text { Deep infection } \\
\text { Non union }\end{array}$ & Screw pull out & yes $3 x$ & $\begin{array}{c}2 \mathrm{x} \text { Implant } \\
\text { exchange (infection) } \\
\text { Bone graft } \\
\text { (non union) }\end{array}$ \\
\hline 6 & $\mathrm{~A} 3$ & Yes & open & Crush kidney Pneumonia & $\begin{array}{l}\text { Compartment } \\
\text { syndrome lower } \\
\text { extremity after } \\
\text { reconstruction } \\
\text { popliteal artery } \\
\text { Deep infection }\end{array}$ & & yes $2 \mathrm{x}$ & $\begin{array}{l}\text { Debridement and } \\
\text { irrigation }\end{array}$ \\
\hline 12 & $\mathrm{C} 3$ & No & open & & Non union & & yes & Bone graft \\
\hline 13 & $\mathrm{C} 3$ & No & open & & $\begin{array}{l}\text { Irritating } \\
\text { screw tip }\end{array}$ & & yes & Irritation screw tip \\
\hline 22 & $\mathrm{C} 3$ & Yes & closed & & & $\begin{array}{l}\text { Screw loosening due } \\
\text { to missing locking cap }\end{array}$ & yes & Screw removal \\
\hline $23 \mathrm{~L}$ & $\mathrm{C} 3$ & Yes & open & & $\begin{array}{l}\text { Superficial } \\
\text { infection }\end{array}$ & & no & $\begin{array}{l}\text { Conservative } \\
\text { management }\end{array}$ \\
\hline
\end{tabular}

similar results regarding union using the same implant with a minimal invasive approach only [10]. Even so, they had proximal and distal femoral fractures in his case series as well as periprosthetic fractures. Pressmar et al. reported a slightly higher major revision rate using the $\mathrm{NCB}^{\circledR}$ DF plate and an implant failure rate of twenty per cent, but they state that an open operative technique was used in $84 \%$ of cases, and it remains unclear which biomechanical principles they applied [11]. This case series included periprosthetic fractures only.

In our cohort the mean HSS Score was 79 (32-99, SD18) with $73 \%$ good to excellent results. In the literature reviewed by Smith et al. [8] similar results have been reported. The mean scores ranged from 74-81 and Syed et al. reported $72 \%$ good to excellent results.

Limitations of our study are that the minimum follow up of one year is only enough to comment on healing and midterm functional results. It can't be commented on the development of degenerative joint disease which would be interesting with such a high rate of intra-articular fractures in our study cohort. Another limitation is that the study cohort is still relatively small with only twenty-six cases meeting the inclusion criteria. Despite the fact that the study cohort consists of a consecutive series of distal femoral fractures, it is a retrospective study.

We believe that the operative technique respecting biologic and biomechanical principles does influence the success of treating these fractures with locking plates significantly $[5,12-13]$. In some cases where open reduction is necessary it is of utmost importance that the muscle and periosteal bone cover is preserved. In cases of comminution, free fragments must be left untouched even in open technique. With a biological fixation technique and a fixedangle implant, the periosteal blood flow remains intact and bone healing is less disturbed. Besides using minimally- invasive techniques, we emphasize to use long plates, to apply bicortical screws, to leave two to three screw holes empty around the fracture gap in simple fractures in order not to create a too rigid construct, and to position the screws adjacent to a comminuted fracture as close as possible to the fracture gap [7].

In summary, good results can be achieved in the treatment of complex distal femoral fractures with the $\mathrm{NCB}^{\circledR}$ DF plate applying these biomechanical principles. It is a safe and simple-to-use implant and the application possibilities are expanded due to the combination of polyaxial screw placement and angular stability.

\section{CONFLICT OF INTEREST}

The authors confirm that this article content has no conflict of interest.

\section{ACKNOWLEDGEMENTS}

Declared none.

\section{REFERENCES}

[1] Frigg R. Locking Compression Plate (LCP). An osteosynthesis plate based on the Dynamic Compression Plate and the Point Contact Fixator (PC-Fix). Injury 2001; 32(Suppl 2): 63-6.

[2] Davison BL. Varus collapse of comminuted distal femur fractures after open reduction and internal fixation with a lateral condylar buttress plate. Am J Orthop 2003; 32(1): 27-30.

[3] Kolb K, Koller H, Lorenz I, et al. Operative treatment of distal femoral fractures above total knee arthroplasty with the indirect reduction technique: a long-term follow-up study. Injury 2009; 40(4): 433-9.

[4] Henderson CE, Lujan TJ, Kuhl LL, Bottlang M, Fitzpatrick DC, Marsh JL. 2010 Mid-America Orthopaedic Association Physician in Training Award: Healing Complications Are Common After Locked Plating for Distal Femur Fractures. Clin Orthop Relat Res 2011; 469(6): 1757-65. 
[5] Greiwe RM, Archdeacon MT. Locking plate technology: current concepts. J Knee Surg 2007; 20(1): 50-5.

[6] Kuster MS GK, Howald R, Forster TN. The influence of screw placement on fracture motion. 9th ESSKA Congress; London 2000; p. 319 .

[7] Stoffel K, Dieter U, Stachowiak G, Gachter A, Kuster MS. Biomechanical testing of the LCP--how can stability in locked internal fixators be controlled? Injury 2003; 34(Suppl 2): B11-9.

[8] Smith TO, Hedges C, MacNair R, Schankat K, Wimhurst JA. The clinical and radiological outcomes of the LISS plate for distal femoral fractures: a systematic review. Injury 2009; 40(10): 104963.

[9] Kregor PJ, Stannard JA, Zlowodzki M, Cole PA. Treatment of distal femur fractures using the less invasive stabilization system: surgical experience and early clinical results in 103 fractures. J Orthop Trauma 2004; 18(8): 509-20.
[10] El-Zayat BF, Zettl R, Efe T, Kruger A, Eisenberg F, Ruchholtz S. [Minimally invasive treatment of geriatric and osteoporotic femur fractures with polyaxial locking implants (NCB-DF(R))]. Unfallchirurg 2010.

[11] Pressmar J, Macholz F, Merkert W, Gebhard F, Liener UC. [Results and complications in the treatment of periprosthetic femur fractures with a locked plate system]. Unfallchirurg 2010;113(3): 195-202.

[12] Erhardt JB, Grob K, Roderer G, Hoffmann A, Forster TN, Kuster MS. Treatment of periprosthetic femur fractures with the noncontact bridging plate: a new angular stable implant. Arch Orthop Trauma Surg 2008; 128(4): 409-16.

[13] Erhardt JB, Kuster MS. Periprosthetic fractures of the knee joint. Orthopade 2009 [Epub ahead of print].

Received: June 26, 2013

Revised: January 22, 2014

Accepted: January 27, 2014

(C) Erhardt et al.; Licensee Bentham Open.

This is an open access article licensed under the terms of the Creative Commons Attribution Non-Commercial License (http://creativecommons.org/licenses/by-nc/3.0/) which permits unrestricted, non-commercial use, distribution and reproduction in any medium, provided the work is properly cited. 